\title{
LA SUPRESIÓN DE LA INQUISICIÓN Y EL CAMINO A LA LIBERTAD RELIGIOSA
}

\author{
HENAR PIZARRO LLORENTE ${ }^{1}$
}

\begin{abstract}
Resumen: El P. Manuel Revuelta, SJ, publicó un artículo en 2013 sobre las dos supresiones que sufrió la Inquisición española durante la Guerra de la Independencia. El trabajo que presentamos pretende ser un homenaje a su forma de abordar este acontecimiento en el contexto histórico de las reformas que acompañaron la llegada de los ejércitos napoleónicos y la celebración de las Cortes de Cádiz. El análisis se pone en relación con uno de los ejes transversales en su obra como fue la política religiosa decimonónica y el arduo camino hacia la tolerancia y la libertad de culto.
\end{abstract}

PalABRAS ClaVE: Inquisición; afrancesados; Cortes de Cádiz; liberales; tolerancia.

\section{The suppression of the Inquisition and the path to religious freedom}

ABSTRACT: Father Manuel Revuelta, SJ, published an article in 2013 about the two suppressions suffered by the Spanish Inquisition during the War of Independence. The work we present is intended to be a tribute to his way of approaching this event in the historical context of the reforms that accompanied the arrival of the Napoleonic armies and the celebration of the Cortes of Cádiz. The analysis is related to one of the transversal axes in his work, such as 19th century religious policy and the arduous path towards tolerance and freedom of worship.

KEY WORDS: Inquisition; frenchified; Cadiz Courts; liberals; tolerance.

El P. Manuel Revuelta, SJ, escribió un artículo titulado «Las dos supresiones de la Inquisición durante la Guerra de la Independencia», que publicó la revista Miscelánea Comillas vol. 71 (2013), núm. 139, pp. 221-263. El tema había sido elegido por el autor para conmemorar el bicentenario de la supresión de la Inquisición por las Cortes de Cádiz, lo que suponía una ocasión para reflexionar sobre la significación de esa medida. El final de la existencia del Santo Oficio fue considerado un hecho de especial relevancia para las dos

1 Profesora del Departamento de Relaciones Internacionales. Universidad Pontificia Comillas. Correo electrónico: hpizarro@comillas.edu. 
Españas en guerra entre 1808 y 1814 . Sin duda, tradicionalmente se ha señalado de manera especial su inclusión en los decretos de Chamartín dictados por Napoleón el 4 de diciembre de 1808. De la misma manera, el debate que culminó con el decreto de suspensión de las Cortes de Cádiz en enero de 1813 fue uno de los más apasionados que se vivieron en el seno de las mismas, cuando las circunstancias bélicas hacían previsible el triunfo español en la contienda. Como señala el P. Revuelta: «Tocar la Inquisición era hurgar en la religión de la nación española, un nervio en carnes vivas que alcanzaba la esencia de España» (p. 222). Resulta por tanto pertinente analizar las claves que pueden explicar los motivos de la transcendencia que se dio a este suceso cuando el Santo Oficio era una institución en evidente decadencia a finales del siglo XVIII. Sin embargo, mantenía muy viva su imagen simbólica como elemento esencial para la conformación de la identidad de la nación española. Por ello, la transformación política que se pretendía llevar a cabo buscaba eliminar esta imponente construcción conceptual.

\section{RASGOS ESENCIALES DE UNA EVOLUCIÓN}

El apasionamiento en torno a la Inquisición estuvo relacionado con que la confesionalidad católica llevaba siglos vinculada a la idiosincrasia de los españoles. Como es bien sabido, la Inquisición española nació para solucionar el problema judeoconverso. Los judíos habían convivido pacíficamente con los cristianos durante la Edad Media, pero no se implicaron en los acontecimientos, especialmente, en el proceso de Reconquista, que centraron los esfuerzos de los cristianos desde el siglo VIII. Se fueron generando por parte de los cristianos unas dinámicas que conglomeraron creencias religiosas, valores sociales y una cultura que se fueron transformando y perduraron a lo largo de los siglos. Los judíos, al no intervenir en este proceso, siguieron ocupados en sus labores económicas y sociales mientras practicaban libremente su religión. Sin embargo, cuando a finales del siglo XIII se detuvo el proceso de Reconquista, los reyes de los distintos territorios peninsulares priorizaron la reorganización política de sus reinos, para lo que las actividades desarrolladas por los judíos resultaron imprescindibles. Los monarcas les ofrecieron el ejercicio de cargos y ocupaciones tanto en el gobierno de las ciudades como en el entorno más cercano de los propios reyes, mientras que los cristianos, retornados a sus lugares de origen tras la lucha contra los musulmanes durante generaciones, encontraron que los miembros de dicha minoría habían ocupado los puestos más destacados y habían ganado 
el favor del monarca. Además del desplazamiento del poder sufrido por los cristianos, agraviaba a estos que los judíos salían beneficiados sin haber padecido los sacrificios de la cruzada. La tensión derivó en los progroms de 1391 y 1412, después de los que un considerable número de judíos se convirtieron al cristianismo con el objetivo de escapar de esta violencia. No obstante, a pesar de su conversión, sincera en muchos casos tras siglos de convivencia, los nuevos cristianos fueron identificables para el resto de la sociedad, tanto por su destacada posición en el gobierno de las ciudades como por el mantenimiento de sus costumbres y referentes, por lo que no se produjo la integración. Su falta de adecuación a la cultura, ideales sociales y forma de vida cristiana en su conjunto sobrepasaba el ámbito de las creencias religiosas. Precisamente, esta inadaptación facilitó a los cristianos viejos el argumento de la falsa conversión y, por tanto, el motivo para su persecución.

Ciertamente, los judeoconversos no entendían la religión de la misma manera que los cristianos viejos, puesto que tenían una vivencia más íntima, con una espiritualidad interiorista y encaminada hacia la mística. Por el contrario, los cristianos viejos vinculaban la religión al desarrollo de actos externos, en los que se ponían de manifiesto los valores que identificaban al grupo social. Por tanto, la espiritualidad se fijaba más en los signos y en el cumplimiento de normas exteriores con una orientación ascética. En consecuencia, desde sus orígenes, la Inquisición se conectaba a una realidad donde se encontraban imbricados aspectos religiosos, políticos y sociales. La presión de los cristianos viejos sobre los Reyes Católicos se encontraba al punto de desembocar en levantamientos sociales y guerras, por lo que se aceptó la demanda de solicitar la creación del Santo Oficio, cuya bula fundacional fue extendida el 1 de noviembre de 1478 por el papa Sixto IV. Efectivamente, pronto se comprobó que el nuevo tribunal extendía sus intereses más allá de la persecución de la ortodoxia católica, puesto que uno de sus principales objetivos fue despojar a los judeoconversos de sus cargos, que pasaron a ser ocupados por aquellos que se identificaban con la ideología de los "cristianos viejos» y había abogado por la implantación de la Inquisición. Esta cuestión fue determinante para la conformación de las facciones cortesanas, puesto que los servidores cercanos a la reina Isabel, que compartían esta visión interiorista y observante de la religión, fueron desbancados por los "fernandinos», que lograron alcanzar a través del control de la Inquisición los principales puestos en las ciudades castellanas y en la administración de la Monarquía, sobre todo tras el fallecimiento de la Reina Católica, mientras que la religiosidad de este grupo isabelino comenzó a ser mirada con reticencia y sospecha. Evidentemente, la Inquisición había sido la herramienta que había facilitado la sustitución de una élite por 
otra, puesto que judeoconversos había igualmente en ambas facciones. Así pues, los distintos grupos políticos mostraron también sus diferencias en los planteamientos religiosos y culturales, lo que se ha de considerar cuando se valora la evolución posterior de la institución inquisitorial.

Sin pretender realizar en este breve espacio una descripción del devenir inquisitorial, conviene exponer algunas claves que nos acerquen cronológicamente al momento de las citadas supresiones. La otra minoría religiosa existente a comienzos del siglo XVI fueron los moriscos, cuyo tratamiento fue muy diferente al carecer como colectivo de relevancia política, económica o social. Las convulsiones políticas que precedieron la llegada de Carlos $\mathrm{V}$ al trono y las vicisitudes sufridas por el Santo Oficio en este periodo condicionaron que la atención a este colectivo se demorase hasta 1526. La celebración de juntas específicas deparó el establecimiento de Concordias, que prologaron hasta mitad de la centuria el proceso de conversión y catequización a cambio del pago de ciertas cantidades de dinero. No obstante, el interés del Santo Oficio estaba orientado al surgimiento de varias corrientes religiosas en Castilla. Los movimientos de reforma y observancia habían deparado, entre otras cuestiones, una mayor tolerancia hacia las formas de piedad popular, la traducción de obras de devoción, la fundación de la Universidad de Alcalá de Henares, el surgimiento de algunos grupos heterodoxos, como los alumbrados, o practicantes de una espiritualidad ortodoxa como los recogidos. Sin duda, este fermento supuso un excelente vehículo de difusión para el humanismo erasmista bajo el paraguas del Inquisidor General Alonso de Manrique, que sustentó las propuestas de renovación a la par que potenció la persecución de la herejía. Sin embargo, a lo largo de la década de 1530 se fueron produciendo una serie de cambios ideológicos e intelectuales, vinculados a la caída de Mercuriano de Gattinara y el ascenso de asesores hispanos vinculados al grupo "fernandino», identificados con los valores de los «cristianos viejos». La «facción castellana» fue heredera de los mismos y utilizó la Inquisición para imponer sus planteamientos a través de la actuación del Inquisidor General Juan Pardo de Tavera, dando paso a un periodo marcado por el «neohidalguismo» y los Estatutos de limpieza de sangre, a pesar de las reticencias con que el papado veía esta fórmula de exclusión social.

El cambio generacional se produjo con la llegada de Fernando de Valdés al cargo de Inquisidor General en 1547. Así mismo, también se mutaron las prioridades del tribunal, que orientó su actividad al control del tráfico de libros, a la vigilancia de las fronteras para evitar el «contagio» de pensamiento heterodoxo, y a la persecución del luteranismo, entre otras cuestiones. No obstante, para el tema que nos ocupa, cabe destacar que fue bajo su mandato 
cuando se realizó una reorganización del Consejo y de los tribunales de distrito, a cuyo frente puso a sus hechuras, y consiguió establecer una unidad procesal a través del establecimiento de cartas acordadas, que dieron lugar a una nueva Compilación de Instrucciones del Santo Oficio (1561), que se mantuvo vigente hasta la supresión de la Inquisición. La llegada de Felipe II al trono supuso la puesta en marcha del proceso de confesionalización de la Monarquía, que deparó un fortalecimiento del Santo Oficio y la caracterización de la actuación del tribunal como un arma de control social cifrada en la persecución de cualquier ideología herética o disidente que pudiese derivar en un conflicto sociopolítico. Diego de Espinosa fue el Inquisidor General encargado de realizar los ajustes para adecuar a la Inquisición a las nuevas exigencias: se tomaron medidas para cubrir todo el ámbito geográfico, incrementó la cobertura espacial a través de la red de comisarios y familiares, y se potenció la realización de un nuevo catálogo de libros prohibidos. Si bien se trataba de adecuar esta actividad a las normas tridentinas, no se renunciaba a incorporar las peculiaridades de los listados realizados por la Inquisición española.

La religiosidad impulsada por el proceso de confesionalización fue muy formalista e intelectual, lo que favoreció su vigilancia y control. La ruptura se produjo por parte de algunas órdenes religiosas, que excedieron los límites de la reforma proyectada por el rey para impulsar una espiritualidad radical que encontró el apoyo del papa. Los problemas que tuvieron con el Santo Oficio algunos de los miembros más destacados del movimiento descalzo o recoleto se inscribieron en el conflicto desatado por ambas instancias para salvaguardar su ámbito de influencia. Frente a los letrados castellanos implicados en el proceso de confesionalización, se conformó una facción "papista», que fue evolucionando en los decenios siguientes a la par que los sucesivos papas fueron consolidando un proyecto de reestructuración de la Iglesia que culminó en el pontificado de Clemente VIII (1592-1605). Los resultados del proceso se concretaron en diversas manifestaciones, pero conviene destacar que se inscribieron en las pautas de lo que se ha venido describiendo como «disciplinamiento social», mientras que Roma se ratificó como referente único del mundo católico sin permitir interferencias de otras instancias.

No es casual que fuese en este contexto cuando se iniciaron los debates en torno a la jurisdicción del Consejo de Inquisición. La tensión entre el «papista» Gaspar de Quiroga y los miembros «castellanistas» del Consejo, órgano que dependía completamente de la jurisdicción temporal del rey y que carecía de facultades propias delegadas por el papa, se manifestó en la pretensión de dicho organismo de ampliar su jurisdicción en detrimento de los poderes del Inquisidor General, quien recibía a través de su nombramiento 
las competencias emanadas del pontífice. Esta pugna fue adquiriendo un nuevo carácter tras las primeras décadas del siglo XVII, cuando la actividad procesal del Santo Oficio sufrió un marcado descenso. Durante el reinado de Felipe IV, la discusión sobre la jurisdicción de la Inquisición y sus órganos de gobierno se vinculó al menoscabo que los réditos políticos de la Monarquía habían sufrido como consecuencia de la subordinación a los intereses pontificios durante el reinado anterior. La necesidad de diferenciar las esferas provocó la distinción nítida en el ámbito jurisdiccional. La disputa se fue incrementando hasta que, en 1643, el rey determinó colocar al Inquisidor General y a su jurisdicción privativa bajo su potestad. El pensamiento regalista de la segunda mitad del siglo XVII se rigió por este principio. Se dejaba cualquier consideración religiosa vinculada a la actuación inquisitorial a la competencia eclesiástica, pero pertenecía al rey la responsabilidad de intervenir en las cuestiones que afectaban a la actividad de la Inquisición referida a su funcionamiento interno y la calidad de sus servidores, su interacción con otras instituciones de la Monarquía, los asuntos vinculados a la hacienda, etc. Por tanto, en este entendimiento, el Inquisidor General también quedaba bajo las directrices del rey. Frente a esta opción, que contaba con defensores dentro del Santo Oficio, se posicionaron aquellos que defendieron la condición apostólica de la Inquisición bajo la dirección del Inquisidor General. La evolución del conflicto deparó la progresiva supresión de los beneficios temporales que los distintos monarcas habían ido otorgando desde su fundación. En este sentido, en los últimos decenios de la centuria, se pueden rastrear claramente los antecedentes de las reformas que se llevaron a cabo de forma inmediata durante el siglo de la Ilustración. Así, la «Junta Magna» de 1696 abundaba en la reducción de la jurisdicción temporal de la Inquisición y limitaba su actividad a los asuntos religiosos y espirituales. Si bien sus conclusiones quedaron solo en un proyecto, la reforma propuesta fue asumida por Melchor de Macanaz en 1714.

\section{LOS PLANTEAMIENTOS EN TORNO A LA SUPRESIÓN}

En la última etapa de su existencia, la Inquisición, como otras instituciones eclesiales, fue perdiendo progresivamente prestigio entre los españoles. El objetivo de avanzar en la secularización del Estado sostuvo las reformas regalistas que acompañaron la llegada de la nueva dinastía. En este sentido, se insistió en la necesidad de suprimir o reformar el sistema censorio inquisitorial. La pretensión de Macanaz fue que tanto la realización de la propia 
calificación como el entendimiento del delito correspondiese a los tribunales civiles, aun cuando el tema afectase a cuestiones de fe. Sin embargo, el cambio político que trajo aparejado el segundo matrimonio de Felipe V mostró que tanto aquellos sectores relegados del primer equipo reformador como los defensores de la Inquisición contaban con una importante influencia. El ascenso del "partido español», heredero de los viejos ideales de la Monarquía de los Austrias, hizo reverdecer la actividad inquisitorial, y un miembro destacado de dicho grupo, José Camargo, asumió el cargo de Inquisidor General.

Mientras que, en la primera mitad del siglo XVIII, el Santo Oficio centró su actividad en contra del jansenismo, en la segunda se ocupó en la persecución de las ideas ilustradas, aunque los ilustrados españoles fueron mayoritariamente pensadores críticos pero ortodoxos. Ninguno de ellos había tenido excesivas dificultades para acceder a la literatura política extranjera, señaladamente francesa, de manera que hay que reconsiderar el efecto que tradicionalmente se ha atribuido a la censura inquisitorial sobre la intelectualidad española. Así mismo, el Santo Oficio comenzó la persecución contra los masones, que contaban con cierta presencia en Madrid, Barcelona y Cádiz. Si bien el número de procesos en los decenios precedentes había sido escaso, a partir de 1789 sufrió un marcado incremento y significación, puesto que fueron procesados bajo esta acusación disidentes, liberales o revolucionarios. Así, durante el reinado de Carlos IV, la Inquisición volvía a convertirse en un instrumento de control social e ideológico para la Monarquía. A pesar de su merma de jurisdicción, Floridablanca encontró en el Santo Oficio una herramienta eficaz para establecer un «cordón sanitario».

Como nos muestra el P. Revuelta en su estudio, la polémica en torno a la supresión de la Inquisición se inscribió en una circunstancia de guerra y de cambio de sistema político. No había enfrentamiento entre los bandos en la defensa de la religión católica de forma exclusiva y excluyente. Los partidarios de José I, lo que incluía a los obispos y clérigos afrancesados, pudieron apoyarse en el contenido del Estatuto de Bayona. Del mismo modo, el artículo 12 de la Constitución gaditana establecía la defensa del catolicismo. La cuestión se percibió por ambas facciones al margen de las libertades y de los derechos individuales. En el caso de los franceses, hubiese sido muy perjudicial para su gobernación atentar por esta vía contra la abrumadora mayoría sociológica católica y facilitar una justificación religiosa a una previsible resistencia o al estallido de una revuelta. Precisamente, los que hicieron la guerra en nombre de Fernando VII utilizaron la religión durante la contienda apelando al viejo espíritu de cruzada. Además, para aquellos que eran liberales, la imposición de la confesionalidad católica estaba ligada de manera incuestionable con la identidad cultural nacional y no con la libertad 
individual, por lo que no consideraban que se viese conculcada. Para los defensores de la Inquisición, principalmente los partidarios del absolutismo, esta ausencia de tolerancia religiosa justificaba la existencia del tribunal, cuestión que les distanciaba, entre otras muchas, de afrancesados y liberales. Para estos, como quedó reflejado en sus programas políticos, era fundamental la reforma de la Iglesia, a la que también se oponía el grupo partidario del Santo Oficio. La pretendida reforma eclesiástica tenía como objetivo esencial la adaptación de las estructuras externas eclesiales a sus respectivos sistemas políticos. Frente al regalismo de los afrancesados y liberales, se alzó la fórmula ultramontana de los partidarios del mantenimiento de la Inquisición.

El P. Revuelta también nos clarifica en su trabajo las coincidencias y divergencias existentes en la reforma eclesiástica que afrancesados y liberales pretendían implementar, si bien nos advierte que las diferencias afectaban también al «ritmo, cronología, intensidad y método» (p. 225). Hemos elaborado la siguiente tabla siguiendo su clasificación:

\begin{tabular}{|l|l|}
\hline \multicolumn{1}{|c|}{ COINCIDENCIAS } & \multicolumn{1}{c|}{ DIFERENCIAS } \\
\hline $\begin{array}{l}\text { Un ideario acorde a la nueva etapa de } \\
\text { la evolución española }\end{array}$ & $\begin{array}{l}\text { En general, afectaron más a la forma que } \\
\text { al fondo }\end{array}$ \\
\hline $\begin{array}{l}\text { La reforma o supresión de algunas ins- } \\
\text { tituciones eclesiásticas }\end{array}$ & $\begin{array}{l}\text { Afrancesados: reformas rápidas, profun- } \\
\text { das, por vía ordenacista. Muy avanzadas, } \\
\text { no se culminaron a causa de la guerra. }\end{array}$ \\
\hline $\begin{array}{l}\text { Control de la jerarquía eclesiástica para } \\
\text { gobernar la Iglesia desde el Estado }\end{array}$ & $\begin{array}{l}\text { Cortes de Cádiz: reforma más tardía, len- } \\
\text { ta, parlamentaria y moderada }\end{array}$ \\
\hline
\end{tabular}

La Inquisición se entendía como un tribunal disruptivo con el ideario que tanto afrancesados como liberales querían establecer, por lo que debía desaparecer, mientras que la Iglesia debía acomodarse a una legislación que explicitaba la soberanía nacional y el poder del Estado. En este sentido, el Santo Oficio no era un caso único en la proyectada extinción de instituciones eclesiales que no encajasen en los respectivos sistemas en el ámbito económico o socioeclesial. La desamortización y la exclaustración dieron buena muestra de ello. Así mismo, la creación de una Iglesia nacional controlada por el Estado y lo más ajena posible a las directrices del papa se puso en marcha a través del mecanismo esencial de fortalecer el poder de los obispos limitando las reservas pontificias según se recogía en las tendencias galicana, regalista y episcopalista. Estas, a su vez, contenían un potente argumentario contra la Inquisición en cuanto tribunal pontificio. 
Sin embargo, existió otra dimensión de gran interés en la discusión sobre la supresión del Santo Oficio por parte de las Cortes de Cádiz y que, a través de la prensa, se extendió al conjunto de la población. La cuestión esencial era que su existencia no se trataba de una imposición foránea, puesto que su fundación se debió a un deseo expreso de los españoles. El debate abierto sobre la Inquisición se convirtió en un juicio sobre el pasado, pero también en una definición de presente y una proyección sobre el futuro de España. Efectivamente, la existencia de la Inquisición había obedecido intereses de origen interno, pero, evidentemente, también hubo quien se opuso a su presencia y actuación desde su nacimiento. Entre quienes manifestaron sus mayores críticas, se encontraron los colectivos de víctimas, quienes pusieron de manifiesto los intereses que se encontraban detrás de la existencia de la institución inquisitorial desde el comienzo, así como de aquellos que controlaban el tribunal. Los judeoconversos conformantes del grupo isabelino reivindicaron la sinceridad de sus conversiones al cristianismo a través de voces influyentes como la del cronista Hernando del Pulgar entre otros. Así mismo, se pudo constatar que la actuación inquisitorial perseguía la consecución de un cambio de élite en el gobierno de las ciudades castellanas y en el entorno de los reyes, que pasaron a ser ocupados por aquellos que se identificaban con los valores de los «cristianos viejos». La vigorización de la actividad inquisitorial en el siglo XVI no escapó a la polémica en todas sus actuaciones, como la ejecutada sobre los moriscos, y, sin duda, la implicación en la puesta en práctica de los Estatutos de limpieza de sangre, que, con un componente religioso, condicionaban una exclusión política y social. Las críticas contra esta imposición de los valores de la facción "castellana» fue asumida, entre otros, por fray Agustín Saluccio. No obstante, la obra que marcó en gran medida el nacimiento de la leyenda negra sobre la Inquisición fue la obra conocida como "Reginaldo Montano», escrita por un protestante español a mediados del siglo XVI. La divulgación de tormentos y torturas dio la oportunidad a que en las críticas llegadas desde territorios como los Países Bajos o Inglaterra se resaltase esta crueldad y la imposibilidad de desarrollar una libertad de pensamiento, mientras que desde Francia se aludió a la falacia que suponía apoyar en una justificación religiosa la actividad de una institución que estaba al servicio del rey.

Evidentemente, las críticas contra el Santo Oficio arreciaron en los últimos decenios de su existencia. La institución había entrado en decadencia, lo que se reflejaba en la pérdida de rigor y en la falta de celo por parte de sus servidores. Ciertamente, la Ilustración traía a Europa el debate sobre la dialéctica entre la fe y la razón. Las luces ilustradas ponían el foco en el progreso de la civilización y en la libertad de pensamiento. Sin embargo, la 
Monarquía hispana se había identificado con la defensa de la ortodoxia católica, que había puesto en manos del Santo Oficio. Con el cambio de dinastía a comienzos del siglo XVIII, se fue alimentando el argumento de que la decadencia de España se había iniciado con unos reyes que habían primado y utilizado todos sus recursos en la defensa de la religión católica, para lo que no habían dudado en permitir la persecución de la cultura para salvaguardar la ortodoxia por parte de la Inquisición, provocando el consiguiente retraso cultural. La independencia de la Inquisición en materia de censura quedó reducida durante el reinado de Carlos III. Muchos eclesiásticos colaboraron en este proceso, poniendo de manifiesto la división existente en la jerarquía eclesiástica. El filojansenismo favoreció que el Estado fuese asumiendo la labor censora del tribunal inquisitorial para poder ejercer de manera directa el control ideológico y cultural. Rozando el final de la centuria, Jovellanos expuso a Carlos IV su criterio sobre la Inquisición. Señalaba que la ineficacia del tribunal era consecuencia de que sus servidores eran miembros de las órdenes religiosas caracterizados por la ignorancia y por buscar pequeños privilegios a través de esta ocupación. En su opinión, esta labor debía conferirse a los obispos. Sin embargo, su escrito coincidió con la polémica levantada por el obispo constitucional de Blois, quien invitaba a Manuel Godoy a inmortalizar su nombre procediendo a la supresión del Santo Oficio. Sin duda, los argumentos de Henri Grégoire superaban los planteamientos de los liberales españoles al defender la libertad religiosa. No obstante, sus argumentos, expresados de forma fácilmente comprensible sobre la Inquisición como institución antagónica del espíritu del Evangelio, de los derechos del Hombre y de la soberanía popular fueron asumidos por los afrancesados y en parte por los liberales reunidos en las Cortes gaditanas.

\section{EL DESARROLLO DEL DEBATE}

La supresión realizada por Napoleón (4 de diciembre de 1808) se vio favorecida por la dimisión del último Inquisidor General, Ramón José de Arce (1798-1808), tras el motín de Aranjuez. La abolición no causó ningún problema en la España josefina, puesto que se trataba de un anhelo largamente perseguido por el cristianismo ilustrado. Además, la medida contó con el respaldo de influyentes escritores como el académico de la Historia y consejero de Estado Juan Antonio Llorente, autor de la obra más decisiva y divulgada contra la Inquisición, aunque, como es sabido, dista de ajustarse de manera precisa a la realidad histórica. Sin embargo, el pueblo, en cuyo nombre se 
sustentaba la reforma y al que se afirmaba liberar de una institución odiosa, reaccionó con indiferencia o con indignación, lo que fue utilizado por los defensores del Santo Oficio como argumento durante la celebración de las Cortes de Cádiz. Tildaron a los liberales españoles de ser meros imitadores de Napoleón en su propuesta de poner fin al tribunal. Por su parte, estos, de acuerdo con la liquidación decretada por los franceses, acusaron a dicho grupo de realizar una defensa interesada por estar vinculada a sus propios intereses, por lo que no admitirían ni ésta ni ninguna reforma que fuese en contra de los mismos, aunque se considerase de utilidad común, como se había puesto en evidencia en su oposición a la supresión de los señoríos.

Los intentos de restablecer la Inquisición en los territorios liberados de los franceses fueron dificultosos. La abolición había dispersado a los inquisidores de los tribunales de distrito y a los miembros del Consejo Supremo, mientras que la carencia de un Inquisidor General desde marzo de 1808 vino a aumentar las complicaciones para su reorganización. No obstante, los defensores del Santo Oficio afirmaron que correspondía al Consejo el ejercicio de la jurisdicción durante la sede vacante. Por ello, centraron sus esfuerzos en la recomposición del Consejo para que retomase la actividad y despachase por sí solo. Sin embargo, los opositores entendían que esta pretensión era inviable. Como hemos referido, esta posibilidad no era novedosa en la evolución inquisitorial, puesto que los poderes que correspondían al Consejo en sede vacante se habían explorado tras la polémica generada a la muerte del Inquisidor General Garpar de Quiroga.

Los defensores de la Inquisición buscaron el apoyo de la regencia y de las Cortes. En su estudio, el P. Revuelta nos hace un pormenorizado análisis del diario de sesiones y de las distintas visiones existentes sobre esta cuestión (pp. 238-240). El nombramiento de una comisión especial para dirimir la conveniencia o no de restablecer el Consejo de Inquisición en sus funciones propició que los opositores de esta acción pudieran ganar tiempo a través del voto particular del diputado Muñoz Torrero solicitando que se recabase la opinión de los obispos. El objetivo esencial de esta actuación fue eludir un debate que previsiblemente hubiesen perdido. El 19 de marzo de 1812 se proclamó la Constitución de Cádiz. Un mes después, la Comisión presentaba ante la asamblea su dictamen favorable al restablecimiento de la Inquisición. No obstante, Muñoz Torrero volvió a dar un giro a la situación al plantear si esta reactivación el Santo Oficio era compatible con la Constitución recién estrenada. La discusión se desviaba y ponía el foco en una cuestión de compatibilidad sobre la existencia del dicho tribunal y su encaje con el texto constitucional. 
Así pues, la Comisión de Constitución fue la encargada de elaborar un dictamen sobre este asunto. El Dictamen definitivo, leído en las Cortes en diciembre de 1812, valoraba como la Inquisición, cuyo sistema se sustentaba en las Instrucciones establecidas por el Inquisidor General Fernando de Valdés en 1561, era incompatible con la Constitución, la soberanía nacional y con la libertad individual. Sin embargo, esta última cuestión no se relacionaba con la libertad religiosa, sino con las consideraciones realizadas en relación a los sistemas de enjuiciamiento. Sobre la base del trabajo realizado por la Comisión se presentó un proyecto de ley, que recogía un capítulo sobre los tribunales protectores de la religión y otro sobre la prohibición de escritos contrarios a la misma. La división entre los miembros de esta se volvió a reflejar en los votos particulares. Así se leyó aquel que proponía el mantenimiento de la Inquisición procediendo a la reforma de todas aquellas incompatibilidades detectadas respecto a la Constitución, mientras que otros diputados volvieron a requerir la consulta a los obispos y posponer la toma de medidas concretas.

El desarrollo del debate estuvo salpicado por intentos de lograr su interrupción, pero, más que ceñirse a la letra de las propuestas o medidas, ambos bandos acabaron argumentando a favor o en contra de la Inquisición en su conjunto, más allá de la situación o los objetivos precisos, y para ello hicieron acopio de un arsenal de argumentos históricos, jurídicos, económicos, políticos y teológicos. Los intervinientes contrarios a la Inquisición fueron inclinando la balanza de las discusiones hacia sus intenciones. Especialmente elocuente fue el sacerdote canario José Ruiz Padrón, quien, exhibiendo una oratoria magistral, pronunció un discurso de enfoque religioso, donde estableció como la Inquisición era inservible para la Iglesia, era opuesta a la Constitución y contraria al espíritu del Evangelio. En su opinión, la defensa del Santo Oficio resultaba incomprensible, así como inviable cualquier intento de reforma. Los alegatos de los defensores de la Inquisición fueron menos sólidos, pero contaron con el apoyo de las peticiones de diversa procedencia que llegaban a las Cortes. Sin embargo, a pesar de que la última intervención a cargo del diputado Antonio Alcayna insistió en la validez de los elementos esenciales que justificaban la existencia del tribunal y en la posibilidad de acabar con los secundarios o circunstanciales, que siempre quedaron sujetos a reforma, la evolución del debate había mostrado que la suerte de la Inquisición estaba decidida. El 22 de enero de 1813, el resultado de la votación estableció la incompatibilidad de la Inquisición con la Constitución y la supresión de hecho del Santo Oficio.

Quedaba por desarrollar la tarea de sustituir a la Inquisición en la defensa de la religión católica. La propuesta se componía de los tribunales de 
la fe, que no condicionaban las facultades de los obispos para intervenir en las causas de fe como jueces eclesiásticos, mientras que la aplicación de las penas temporales quedaba cometida a los jueces civiles. El funcionamiento práctico de dichas instancias, especialmente de los tribunales de la fe, y la relación entre ellas, principalmente cuidada en los detalles referentes a la prohibición de escritos contra la religión, se plasmó en el decreto firmado el 22 de febrero de 1813. Se aplicó el regalismo que sustentó todas las reformas eclesiásticas y que, también en el caso de la Inquisición, encontró el apoyo del jansenismo, episcopalismo y nacionalismo religioso.

Realmente, se estaba sustituyendo una inquisición por otra, puesto que solo cambiaba el sistema que sustentaba la persecución de la herejía, haciéndola compatible con la Constitución a través de restablecer el procedimiento contemplado en las Partidas (ley II, título XXVI, Partida VII). Se establecía de esta manera la supremacía del poder civil. Mientras, los ultramontanos defensores del Santo Oficio argumentaban que la Iglesia era la única que debía ocuparse de su propia reforma y que las Cortes no podían decretar la supresión de una institución creada por el papa, que además veía discutida su supremacía frente al episcopalismo. En la práctica, el propio decreto entorpecía su aplicación con sus muchas contradicciones. La forzada colaboración entre los jueces eclesiásticos y seglares, cuyas mutuas reticencias imposibilitaban un trabajo conjunto y era propicio a la generación de situaciones incómodas entre las distintas instancias, influyó en que no fuese operativo. Realmente, los nuevos tribunales de la fe no llegaron a constituirse, puesto que el decreto no se puso en ejecución. Si bien la Regencia hizo que el manifiesto y el decreto se leyese en las iglesias tan pronto como se producía la retirada de los franceses, no se puso en aplicación, pero sí se pudo constatar la resistencia y el rechazo que despertaba en el seno de la Iglesia española.

\section{EL LARGO CAMINO A LA TOLERANCIA Y LIBERTAD RELIGIOSA}

Uno de los argumentos esenciales de los liberales se había apuntalado en la Historia y los métodos de la Inquisición. Los datos y la evolución histórica de la institución habían consumido gran parte de los debates mantenidos. Si bien los apuntes esgrimidos fueron bastante ajustados a realidad, se sacaron de contexto o se sustentaron con documentos incompletos. Semejante afirmación se puede realizar en la descripción de los métodos usados por el Santo Oficio. No se buscaba poner de manifiesto una verdad histórica, sino usar la Historia como argumento contra la Inquisición. Además, entre las 
consideraciones esgrimidas por los liberales, ampliamente repetida en los discursos, quedaba sin desarrollo posterior aquella que hizo referencia a la tolerancia evangélica. Entendían que su aplicación no impedía la prohibición sobre la práctica de otras religiones. Se condenaba a la Inquisición por establecer un exclusivismo religioso, pero no se avanzaba en el camino de la libertad religiosa. Se estimaba un cambio inconveniente, puesto que el apasionamiento en relación a la religión, el catolicismo sociológico y su vinculación a la identidad nacional desaconsejaban iniciar esa andadura en la coyuntura política existente. La unidad religiosa se entendía como un bien a proteger por las leyes civiles, si bien no era una exigencia del catolicismo como tal. Se prefería esta solución a la posibilidad de que una apertura a la tolerancia pudiese generar división y discordia. Por tanto, la tolerancia de culto no estaba entre los objetivos de los liberales detractores del Santo Oficio, para algunos por convicción, pero, principalmente, como en el caso de Nicolás Argüelles, porque no creían que las circunstancias políticas fueran las idóneas para enfrentar al país con un tema que traería enorme controversia.

Las últimas décadas de funcionamiento del Santo Oficio han sido objeto de excelentes trabajos en los últimos años. Fernando VII volvió a restablecer la Inquisición el 21 de julio de 1814, si bien volvió a ser abolida durante por el régimen liberal instaurado en 1820. Tras la intervención de la Santa Alianza, solo el deseo del rey de no contravenir a sus aliados europeos hizo que los tribunales inquisitoriales no fueran restaurados, pero la Inquisición siguió constituyendo un símbolo de la unión entre el Trono y el Altar, así como de la derrota del liberalismo. Con la muerte del monarca en septiembre de 1833, y en el escenario político de la Regencia, se publicó el decreto de supresión de la Inquisición el 15 de julio de 1834. Esta ocasión resultó ser definitiva.

Sin duda, la desaparición del Santo Oficio suponía un paso esencial en el camino hacia la tolerancia, pero las circunstancias políticas y sociales impidieron que, desaparecido este escollo, fuese posible el establecimiento de la libertad religiosa. Como concluye el P. Revuelta en su artículo, el debate mantenido por las Cortes de Cádiz no fue estéril, pero "Quedaba un largo camino para la separación Iglesia-Estado y para la libertad de las conciencias. La tolerancia religiosa se implantó en las Cortes progresistas de 1855, y la libertad de cultos en las Cortes democráticas de 1869».

Evidentemente, durante los decenios que transcurrieron desde la supresión de la Inquisición y la libertad religiosa, más de treinta años, el debate se continuó desarrollando. Ciertamente, en lo referido al Santo Oficio, no se incorporaron elementos novedosos, salvo que su existencia se utilizó de manera explícita para denigrar a la Iglesia católica. La nación y la libertad 
constituyen dos ejes esenciales del pensamiento liberal, así como el afán de secularización, y su cimentación convirtió la Historia en campo de operaciones para el liberalismo emergente. No corresponde adentrarse en el «problema religioso» de la España decimonónica, pero se pueden resaltar una serie de claves para entender el papel que se otorgó a la Inquisición en el mismo. Entre las afirmaciones realizadas en los debates habidos en las Cortes de Cádiz, se constituyó como un lugar común que la grandeza de la obra política de los Reyes Católicos, por el avance que suponía hacia la pretensión liberal de unidad, se había visto enturbiada por el establecimiento del tribunal del Santo Oficio. Sin embargo, peor juicio mereció la gestión realizada por los monarcas pertenecientes a la dinastía Habsburgo, sobre quienes se hizo recaer la responsabilidad de la decadencia española. La traducción del libro de A. Duverine, Cuadro histórico de los abusos y espíritu de reforma política en España (Madrid: Imprenta y Librería de don Ignacio Boix, 1840) vino a suponer un impulso para estos planteamientos, puesto que culpabilizaba a unos monarcas extranjeros de haber establecido una política religiosa intransigente, de haber terminado con las libertades medievales (en este sentido, las Comunidades de Castilla fueron el principal referente a lo largo de la centuria), y de haber establecido una intolerancia a través de la Inquisición, que había provocado una situación de retraso cultural.

Para mejor sustentar estas afirmaciones, los historiadores españoles y extranjeros dieron protagonismo en sus estudios a las minorías que había sufrido la persecución inquisitorial y que habían sido discriminados injustamente dentro de la sociedad española. Así, José Amador de los Ríos expuso en su obra Estudios históricos, políticos y literarios sobre los judios en España (Madrid: Imr. De M. Díaz y Comp., 1848), y en otras escritas posteriormente, como en torno a este grupo se iniciaba en España el camino de la civilización burguesa y su devenir tenía un inmediato reflejo en la actividad económica, mercantil e intelectual. En consecuencia, la expulsión de 1492, además del sufrimiento humano causado, terminó con el talento más dinamizador, sobre todo, en el ámbito económico, y la Inquisición ahogó cualquier intento en el plano intelectual. En esta misma interpretación se inscribió la obra del Florencio Janer sobre los moriscos, titulada Condición social de los moriscos de España: causas de su expulsión y consecuencias que esta produjo en el orden económico y social (Madrid: Real Academia de la Historia, 1857), que repetía la visión de esta minoría como víctimas de una monarquía intransigente y cuya expulsión había causado un importante perjuicio económico a la nación española. También obtuvieron atención los protestantes españoles. Así, Adolfo de Castro y Rossi publicaba en 1851 su libro Historia sobre los protestantes españoles y de su persecución por Felipe II (Cádiz: Revista médica), en el que 
seguía las mismas directrices liberales. En trabajos posteriores, su interés se centró en poner de manifiesto las causas de la decadencia española. Su juicio fue rotundo. El catolicismo y la Iglesia católica habían provocado tan nefasta evolución.

De lo expuesto, no resulta difícil deducir que los intelectuales españoles que abordaron esta temática en los decenios del siglo XIX que transcurrieron entre la supresión de la Inquisición y la promulgación de la libertad religiosa estaban proyectando en sus estudios históricos las preocupaciones e intereses que movían el camino de la construcción de un régimen liberal en España. Aplicaron a sus ensayos sobre el Santo Oficio sus propios esquemas y el prisma de los apriorismos derivados de los mismos. A día de hoy, sigue siendo interesante insistir en que cualquier acercamiento que se haga al entendimiento de la Inquisición española debe de considerar ineludiblemente la realidad política y social que provocó su implantación y que sostuvo su funcionamiento durante más de tres siglos. En este sentido, el debate habido en relación con su supresión y en los decenios posteriores aportó muy poco a su mejor conocimiento, puesto que, completamente ideologizado, ignoró cuestiones básicas y llegó a conclusiones bastante desacertadas. El estudio de la Historia requiere del uso correcto de la metodología, de la continuada visita a los archivos para la consulta de las fuentes, de la lectura pausada y respetuosa de los colegas, del juicio ponderado y de la honestidad personal y profesional de la que hizo gala el P. Revuelta, gran historiador de referencia y persona bondadosa. Desde el respeto y el cariño, para él nuestro homenaje y reconocimiento.

\section{REFERENCIAS}

Álvarez Junco, J. (1999). Identidad heredada y construcción nacional. Algunas propuestas sobre el caso español, del Antiguo Régimen a la Revolución Liberal. Historia y Política 2, 123-145.

La Parra López, E. (1985), El primer liberalismo español y la Iglesia. La Cortes de Cádiz. Alicante: Instituto Juan Gil-Albert.

La Parra, E. y Casado, M. A. (2013), La Inquisición en España. Agonía y abolición. Madrid: Los Libros de la Catarata.

Martí Gilabert, F. (1975), La abolición de la Inquisición en España. Pamplona: Universidad de Navarra.

Martínez Millán, J. (2009, 2ª ed.). La Inquisición española. Madrid: Alianza.

- (1985). Los problemas de jurisdicción del Santo Oficio: La Junta Magna (1696). Hispania Sacra 37, 205-259. 
Pérez Villanueva, J y Escandell Bonet, B. (Dirs). (1984). Historia de la Inquisición en España y América. Madrid: BAC.

Revuelta, M. (2013). Las dos supresiones de la Inquisición durante la Guerra de la Independencia. Miscelánea Comillas, 71, 221-263.

Revuelta, M. (2009). El sentido religioso de la Guerra de la Independencia. En J. M. Magaz (ed.), La iglesia en los orígenes de la España contemporánea (pp. 207-281). Madrid: Facultad de Teología de San Dámaso.

Revuelta, M. (2005), «La confesionalidad católica del Estado español en el Concordato y en las Constituciones». En La iglesia española en el siglo XIX. Desafíos y respuestas (pp. 35-79). Madrid: Universidad Pontificia Comillas. 